\title{
Molecular subtype can predict the response and outcome of Chinese locally advanced breast cancer patients treated with preoperative therapy
}

\author{
XIAO SONG CHEN ${ }^{1,2}$, JIA YI WU ${ }^{1,2}$, OU HUANG $^{1,2}$, CAN MING CHEN $^{1}$, JIONG WU $^{1}$, \\ JIN SONG LU ${ }^{1}$, ZHI MING SHAO ${ }^{1}$, ZHEN ZHOU SHEN ${ }^{1}$ and KUN WEI SHEN ${ }^{1,2}$ \\ ${ }^{1}$ Department of Breast Surgery, Cancer Hospital, Fudan University, 270 Dong An Road, Shanghai 200032; \\ ${ }^{2}$ Comprehensive Breast Health Center, Ruijin Hospital Shanghai Jiaotong University \\ School of Medicine, 197 Ruijin Second Road, Shanghai 200025, P.R. China
}

Received November 6, 2009; Accepted January 29, 2010

DOI: 10.3892/or_00000752

\begin{abstract}
We investigated whether molecular subtype can predict the response and prognosis in Chinese locally advanced breast cancer (LABC) patients treated with preoperative therapy. LABC patients treated with preoperative therapy in Cancer Hospital, Fudan University between August 2001 and May 2008 were retrospectively analyzed. Molecular subtypes were constructed from the immunohistochemical results of hormonal receptors (HR) and HER2 status, which were classified as luminal $\left(\mathrm{HR}^{+} / \mathrm{HER} 2^{-}\right)$, triple negative (HR-/HER2-) and HER2 positive subtypes. Preoperative tumor parameters, chemotherapy regimens and response as well as outcome were compared among these subtypes. A total of 225 cases were included into analysis. Univariate and multivariate analysis showed that the pathological complete remission ( $\mathrm{pCR}$ ) independent predictive factors were molecular subtype and preoperative regimens. Compared with luminal subtype, patients with HER2 positive or triple negative tumor had significantly higher $\mathrm{pCR}$ rate, with odds ratio $3.02(95 \% \mathrm{CI}=1.07-8.07 ; \mathrm{P}=0.037)$ and $3.10(95 \%$ $\mathrm{CI}=1.01-9.52 ; \mathrm{P}=0.048)$, respectively. However, HER2 positive or triple negative breast cancer patients were also associated with increased recurrence $(\mathrm{P}=0.072)$ and death rates $(\mathrm{P}=0.019)$ compared with luminal subtype in the whole population, and was especially worse in patients with residual disease after preoperative therapy with decreased disease-free survival $(\mathrm{P}=0.022)$ and overall survival $(\mathrm{P}=0.007)$. Our results show that molecular subtype can predict the response and prognosis of Chinese LABC patients treated with preoperative therapy. Compared with luminal
\end{abstract}

Correspondence to: Dr Kun Wei Shen, Comprehensive Breast Health Center, Ruijin Hospital Shanghai Jiaotong University School of Medicine, 197 Ruijin Second Road, Shanghai 200025, P.R. China E-mail: kwshen@medmail.com.cn

Key words: locally advanced breast cancer, molecular subtype, predictive factor, pathological complete remission, prognosis subtype, patients with HER2 positive or triple negative disease had increased $\mathrm{pCR}$ rates, but associated with significantly worse survival, especially in those with residual disease after preoperative therapy.

\section{Introduction}

Preoperative therapy is the standard treatment for locally advanced breast cancer (LABC), which aims to improve surgical options, obtain freedom from disease and gain information on tumor response (1-3). Several randomized clinical trials have demonstrated that patients achieved pathological complete remission (pCR) after preoperative therapy had better prognosis than those that did not (4-6). Breast cancer is a heterogeneous disease, thefore tumor with the same clinicopathological characteristics may be diverse in disease behavior, response to therapy and outcome. Microarray analysis has identified breast cancer subtypes with different clinical out-comes, including luminal, normal breast-like, Her2/ $\mathrm{Neu}^{+}$, and basal-like subtypes (7-9). Recent report revealed significantly higher $\mathrm{pCR}$ rate to preoperative therapy among basal-like and HER2+ subtypes compared with luminal subtype (10). Carey et al reported that using immunohistochemistry (IHC) to classify tumors according to breast cancer subtype and found that basal-like and HER2 positive subtypes were associated with higher $\mathrm{pCR}$ rate than luminal breast cancers (11). Furthermore, patients with triple negative breast cancer had significantly higher pCR rate compared those with non-triple negative disease, however, triple negative breast cancer patients with residual disease after preoperative therapy had worse prognosis (12). In addition, Yin et al have recently reported that there were some dissimilarity between Chinese breast cancer patients and western population, which raises the question whether this molecular subtype can also predict the response and prognosis in Chinese LABC setting $(13,14)$.

Based on above information, we used IHC to classify Chinese LABC patients with several subtypes and to evaluate whether this molecular subtype was associated with response to preoperative therapy and long-term outcome, including disease-free survival (DFS) and overall survival (OS). 


\section{Materials and methods}

Patients and treatment regimens. This study was retrospectively conducted from a database of patients who underwent preoperative therapy from August 2001 to May 2008 in Cancer Hospital, Fudan University, Shanghai, China. A total of $225 \mathrm{LABC}$ patients were included in this study, they met all of the following criteria: i) female gender; ii) an initial diagnosis of breast cancer with $\mathrm{T}_{3-4}$ any $\mathrm{NM}_{0}$ or anyTN ${ }_{2-3} \mathrm{M}_{0}$ disease according to the sixth edition of the AJCC Cancer Staging Manual; iii) no history of other malignancy; iv) available information on clinical and pathologic tumor size, lymph node, estrogen receptor (ER), progesterone receptor (PR) and HER2 status; v) at least three cycles of preoperative chemotherapy was administered; vi) did not receive trastuzumab-containing preoperative therapy. Follow-up information regarding relapse and survival status was conducted through the retrieval of follow-up medical records kept in the out-patient department and personal contact with the patients.

Preoperative regimens contained vinorelbine plus epirubicin (VE, V $25 \mathrm{mg} / \mathrm{m}^{2}$ i.v. days 1 and 8 plus E $60 \mathrm{mg} /$ $\mathrm{m}^{2}$ i.v. day 1 , repeated every 3 weeks); paclitaxel plus carboplatin $\left(\mathrm{PCb}\right.$, paclitaxle $80 \mathrm{mg} / \mathrm{m}^{2}$ plus carboplatin $\mathrm{AUC}=2$ infusion days 1,8 and 15 , repeated every 4 weeks); cyclophosphamide, epirubicin and fluorouracil (CEF, C $500 \mathrm{mg} / \mathrm{m}^{2}$ i.v., E $75 \mathrm{mg} / \mathrm{m}^{2}$ i.v. and F $500 \mathrm{mg} / \mathrm{m}^{2}$ infusion day 1, repeated every 3 weeks); cyclophosphamide, pirarubicin and fluorouracil (CTF, C $500 \mathrm{mg} / \mathrm{m}^{2}$ i.v., THP $50 \mathrm{mg} / \mathrm{m}^{2}$ infusion, and F $500 \mathrm{mg} / \mathrm{m}^{2}$ infusion day 1 , repeated every 3 weeks); CEF followed by docetaxel $\left(\mathrm{CEF} \rightarrow \mathrm{T}\right.$, docetaxel $75 \mathrm{mg} / \mathrm{m}^{2}$ infusion day 1 , repeated every 3 weeks); and epirubicin plus docetaxel (ET, E $60 \mathrm{mg} / \mathrm{m}^{2}$ i.v., T $75 \mathrm{mg} / \mathrm{m}^{2}$ infusion, every 3 weeks).

IHC pathological analysis and molecular classification. ER, PR and HER2 status of core biopsy samples were assessed by IHC which was carried out in the department of pathology, Cancer Hospital, Fudan University. The cut-off for ER and PR positivity was defined as $>1 \%$ tumor cells with nuclear staining. HER2 was considered positive when HER2 membrane staining was scored $3+$ by IHC or amplification by fluorescence in situ hybridization (FISH), whereas cases with $0-1+$ were regarded as negative. Patients with HER2 ${ }^{++}$were considered as negative without FISH confirmation.

Patients were categorized based on the hormonal receptor (HR) and HER2 status of their primary tumors. HR ${ }^{+}$was defined as $\mathrm{ER} / \mathrm{PR}^{+}$, whereas $\mathrm{HR}^{-}$as both $\mathrm{ER}^{-}$and $\mathrm{PR}^{-}$. These three breast cancer subtypes were classified as follows: luminal ( $\left.\mathrm{HR}^{+} / \mathrm{HER}^{-}\right)^{-}$, triple negative (HR-/HER2-) and HER2 positive.

Statistical analysis. pCR was defined as non-invasive tumor cell in breast and axillary samples. Events for calculation of DFS included all local and regional recurrences, distant metastasis, secondary malignant carcinoma, contralateral breast cancer and all deaths. DFS was measured from the date of initial diagnosis to the date of last follow-up or above events (15). OS was defined as the time interval from the date of initial diagnosis to the date of last follow-up or death. Multinomial logistic regression analysis was used to compare the baseline tumor features between these three subtypes.
Table I. Patient characteristics.

\begin{tabular}{lrr}
\hline Characteristic & No. & $(\%)$ \\
\hline Age at diagnosis & & \\
$\quad \leq 50$ years & 116 & 51.6 \\
$>50$ years & 109 & 48.4 \\
Menopausal status & & \\
Pre/Peri-menopausal & 116 & 51.6 \\
Post-menopausal & 109 & 48.4 \\
Histopathology type & & \\
Invasive ductal carcinoma & 183 & 81.3 \\
Non-invasive ductal carcinoma & 42 & 18.7 \\
Pre-tumor status & & \\
$\mathrm{T}_{0-2}$ & 41 & 18.2 \\
$\mathrm{~T}_{3}$ & 131 & 58.2 \\
$\mathrm{~T}_{4}$ & 53 & 23.6
\end{tabular}

Pre-lymph node status

$\mathrm{N}_{0} \quad 42$

18.7

$\mathrm{N}_{1}$

12.0

$\begin{array}{lll}\mathrm{N}_{2} & 130 & 57.8\end{array}$

$\mathrm{N}_{3} \quad 26$

11.5

Estrogen receptor status

Negative 106

Positive

Progesterone receptor status

Negative 107

Positive

118

HER2 status

$\begin{array}{lll}\text { Negative } & 160 & 71.1\end{array}$

$\begin{array}{lll}\text { Positive } & 65 & 28.9\end{array}$

Molecular subtype

$\begin{array}{lll}\text { Luminal } & 107 & 47.6\end{array}$

$\mathrm{HER}^{+}{ }^{+} \quad 65 \quad 28.9$

$\begin{array}{lll}\text { Triple negative } & 53 & 23.6\end{array}$

Kaplan-Meier probability curves were calculated and tested for differences by log-rank test. All statistical tests were twosided at the $5 \%$ level of significance and were performed using SPSS statistical software version 13.0 (SPSS Co., Chicago, IL). Odds ratios (OR) were presented with their $95 \%$ confidence intervals $(\mathrm{CI})$.

\section{Results}

Patient characteristics and preoperative treatment. A total of 225 patients were eligible for last analysis. The mean age was 49.4 (24-78) years. Expression of ER, PR or HER2 was observed in $119(52.8 \%), 118(52.4 \%)$ and $65(28.9 \%)$ patients, respectively. Patients $(n=53$ and $n=26)$ were diagnosed with $\mathrm{T}_{4}$ tumors and supraclavicle lymph node 
Table II. Patient baseline characteristics stratified by molecular subtype $(n=225)$.

\begin{tabular}{|c|c|c|c|c|c|}
\hline \multirow[b]{2}{*}{ Characteristics $^{\mathrm{a}}$} & \multicolumn{2}{|c|}{$\mathrm{HER}^{+}{ }^{+}$} & \multicolumn{2}{|c|}{ Triple negative } & \multirow[b]{2}{*}{ P-value } \\
\hline & OR & $95 \% \mathrm{CI}$ & OR & $95 \% \mathrm{CI}$ & \\
\hline Age at disgnosis (years) & & & & & 0.039 \\
\hline$\leq 50$ years & 0.90 & $0.38-2.12$ & 2.95 & 1.13-7.74 & \\
\hline$>50$ years & 1 & & 1 & & \\
\hline Menopausal status & & & & & 0.247 \\
\hline Pre/Peri-menopausal & 0.55 & $0.23-1.29$ & 0.53 & $0.21-1.34$ & \\
\hline Post-menopausal & 1 & & 1 & & \\
\hline Histopathology & & & & & 0.802 \\
\hline IDC & 0.80 & $0.35-1.82$ & 0.79 & $0.33-1.86$ & \\
\hline Non-IDC & 1 & & 1 & & \\
\hline Pre-tumor status & & & & & 0.327 \\
\hline $\mathrm{T}_{0-2}$ & 1.80 & $0.64-5.06$ & 2.06 & $0.70-6.05$ & \\
\hline $\mathrm{T}_{3}$ & 2.04 & $0.90-4.64$ & 2.06 & $0.83-5.11$ & \\
\hline $\mathrm{T}_{4}$ & 1 & & 1 & & \\
\hline Pre-lymph node status & & & & & 0.827 \\
\hline $\mathrm{N}_{0}$ & 0.84 & $0.24-2.96$ & 0.81 & $0.24-2.74$ & \\
\hline $\mathrm{N}_{1}$ & 1.03 & $0.27-3.89$ & 0.37 & $0.08-1.66$ & \\
\hline $\mathrm{N}_{2}$ & 0.83 & $0.29-2.39$ & 0.70 & $0.25-1.99$ & \\
\hline $\mathrm{N}_{3}$ & 1 & & 1 & & \\
\hline
\end{tabular}

aThe reference category for subtype characteristics (multinomial logistic regression) is 'Luminal'; OR, odds ratio; CI, confidence interval; IDC, invasive ductal carcinoma.

involvement, respectively. One hundred and seven patients $(47.6 \%)$ were designed as having luminal breast cancer, 65 patients $(28.9 \%)$ as HER2 positive breast cancer and 53 patients $(23.6 \%)$ as triple negative breast cancer (Table I). Overall distribution of age at diagnosis $(\mathrm{P}=0.039)$ was recorded to have a substantial difference among four subtypes. Triple negative subtypes occurred more in younger patients than luminal subtype $(\mathrm{OR}=2.95,95 \% \mathrm{CI}=1.13-7.74)$. There were no significant differences in tumor stage, lymph node involvement, histo-pathology type among these subtypes (Table II).

Of the patients, 147 received anthracycline (non-taxane)containing regimens, including VE, CTF, CEF. Taxane (nonanthracycline)-containing regimens were assigned to 64 patients mainly with $\mathrm{PCb}$ regimen, and 14 patients were treated with $\mathrm{CEF} \rightarrow \mathrm{T}$ or $\mathrm{ET}$ regimen. The mean cycle was 3.97 (3-8). One hundred and eighty-one patients were treated with 3-4 cycles preoperative therapy, and 44 patients received more than 4 cycles of treatment. Additional adjuvant chemotherapy was assigned to patients who did not receive 6 cycles of preoperative therapy and all patients received a total of 6-8 cycles of chemotherapy. In total, 127 patients received adjuvant endocrine therapy and only 3 patients did not receive adjuvant radiotherapy.

Correlation between molecular subtype and $p C R$ to preoperative therapy. Overall, 28 patients (12.4\%) achieved
pCR and 197 patients with residual disease (RD) after preoperative therapy. Triple negative and HER2 positive subgroups were associated with the highest rate of pCR, 17.0 and $18.5 \%$, respectively, whereas luminal tumors had a pCR rate of $6.5 \%$. In multivariate analysis, preoperative therapy regimen and molecular subtype were independent factors to predict the pCR rate. Compared with luminal subtype, increased $\mathrm{pCR}$ rates were observed for patients with triple negative subtype $(\mathrm{OR}=3.10 ; 95 \% \mathrm{CI}=1.01-9.52 ; \mathrm{P}=0.048)$ or HER 2 positive subtype $(\mathrm{OR}=3.06 ; 95 \% \mathrm{CI}=1.07-8.72$; $\mathrm{P}=0.037)$. Furthermore, patients treated with taxanecontaining regimens $(\mathrm{PCb}, \mathrm{CEF} \rightarrow \mathrm{T}$ and $\mathrm{ET})$ were association with higher $\mathrm{pCR}$ rates, $\mathrm{P}<0.001$ (Table III).

Correlation of molecular subtype with prognosis. After a mean follow-up of 32.5 months (8-82 months), 67 cases were recorded to have disease recurrence or death. Forty-six patients died and 21 patients are alive after disease recurrence. The 5-year estimated DFS was $67.4 \%$ for luminal subgroup, compared with $45.1 \%$ for HER 2 positive subtype, and $44.2 \%$ for triple negative disease, respectively ( $\mathrm{P}=0.072$, Fig. 1). In the whole population, luminal subtype was associated with better OS compared with HER2 positive subtype and triple negative disease, the 5-year estimated OS was 78.7, 61.4 and $53.6 \%$, respectively ( $\mathrm{P}=0.019$, Fig. 2). For patients who achieved pCR after preoperative therapy, the DFS was $100 \%$ which was significant higher than patients with $\mathrm{RD}(\mathrm{P}=0.007$, 
Table III. Logistic regression analysis of factors associated with pCR.

\begin{tabular}{|c|c|c|c|c|c|c|}
\hline \multirow[b]{2}{*}{ Characteristic } & \multicolumn{2}{|c|}{ Pathological response } & \multirow{2}{*}{$\frac{\text { Univariate }}{\text { P-value }}$} & \multicolumn{3}{|c|}{ Multivariate analysis } \\
\hline & $\mathrm{pCR}(\mathrm{n}=28)$ & Non-pCR $(n=197)$ & & OR & $95 \% \mathrm{CI}$ & P-value \\
\hline Age at diagnosis & & & 0.303 & & & \\
\hline$\leq 50$ years & 17 & 99 & & Referent & & \\
\hline$>50$ years & 11 & 98 & & 0.95 & $0.28-3.20$ & 0.934 \\
\hline Menopausal status & & & 0.303 & & & \\
\hline Pre/Peri-menopausal & 17 & 99 & & Referent & & \\
\hline Post-menopausal & 11 & 98 & & 0.52 & $0.20-1.36$ & 0.180 \\
\hline
\end{tabular}

Preoperative therapy regimen

Anthracycline (non-taxane)-containing

Taxane (non-anthracycline)-containing

Anthracycline + Taxane

Preoperative therapy cycles

3-4

$>4$

Histopathology type

IDC

Non-IDC

Pre-tumor status

$\mathrm{T}_{0-2}$

$\mathrm{T}_{3}$

$\mathrm{T}_{4}$

Pre-lymph node status

$\mathrm{N}_{0}$

$\mathrm{N}_{1}$

$\mathrm{N}_{2}$

$\mathrm{N}_{3}$

Estrogen receptor status

Negative

Positive

Progesterone receptor status

Negative

Positive

HER2 status

Negative

Positive

Molecular subtypes

Luminal

HER2 positive

Triple negative
108

17

90

107

144

53
$<0.001$

Referent
$\mathbf{9 . 8 3}$

6.77

3.65-26.47

$<0.001$

1.43-31.97 0.016

0.455

Referent

$1.00 \quad 0.20-5.06$

0.996

0.361

Referent

$0.65 \quad 0.22-1.95$

0.642

$\begin{array}{ccc}\text { Referent } & & \\ 0.85 & 0.23-3.13 & 0.802 \\ 1.71 & 0.44-6.63 & 0.440\end{array}$

0.431

$\begin{array}{ccc}\text { Referent } & & \\ 0.27 & 0.04-1.62 & 0.152 \\ 0.31 & 0.10-0.95 & 0.040 \\ 0.55 & 0.12-2.46 & 0.429\end{array}$

0.127

0.136

0.086

0.047

OR, odds ratio; CI, confidence interval; IDC, invasive ductal carcinoma.

Fig. 3), and apt to have better OS ( $\mathrm{P}=0.052$, Fig. 4). In multivariate analysis, a significantly decreased DFS was observed for patients with HER2 positive [hazard ratio $(\mathrm{HR})=2.07$; 95\% CI=1.17-3.67; $\mathrm{P}=0.013)$ ] or triple negative disease
$(\mathrm{HR}=2.02 ; 95 \% \mathrm{CI}=1.09-3.76 ; \mathrm{P}=0.025)$ compared with luminal subtype. Other factors associated with worse DFS were higher tumor stage and higher lymph node stage. Similarly, molecular subtype was also an independent factor 


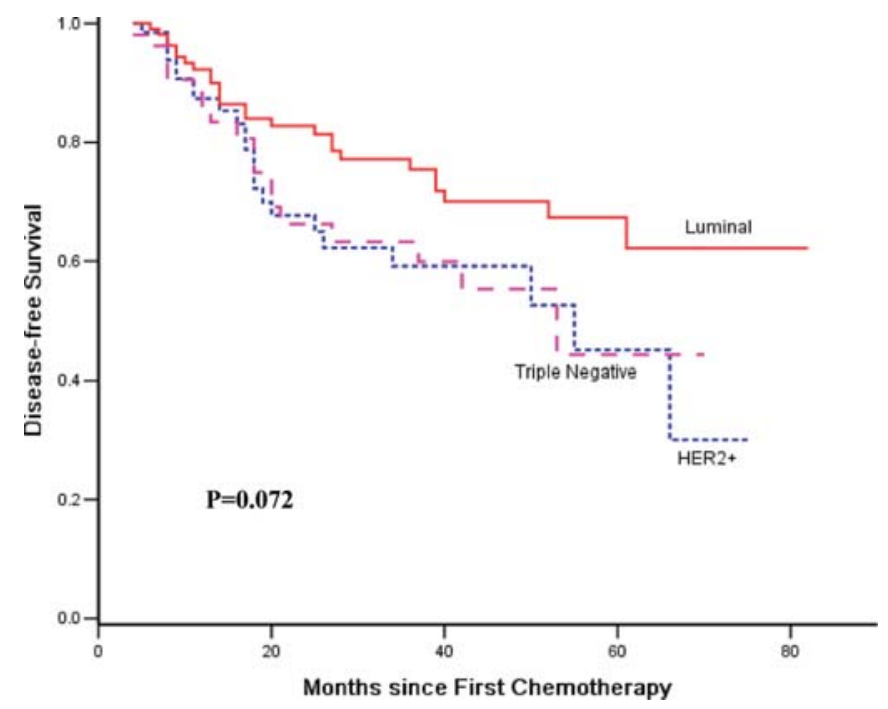

Figure 1. Correlation between breast cancer subtypes and DFS in the whole patients.

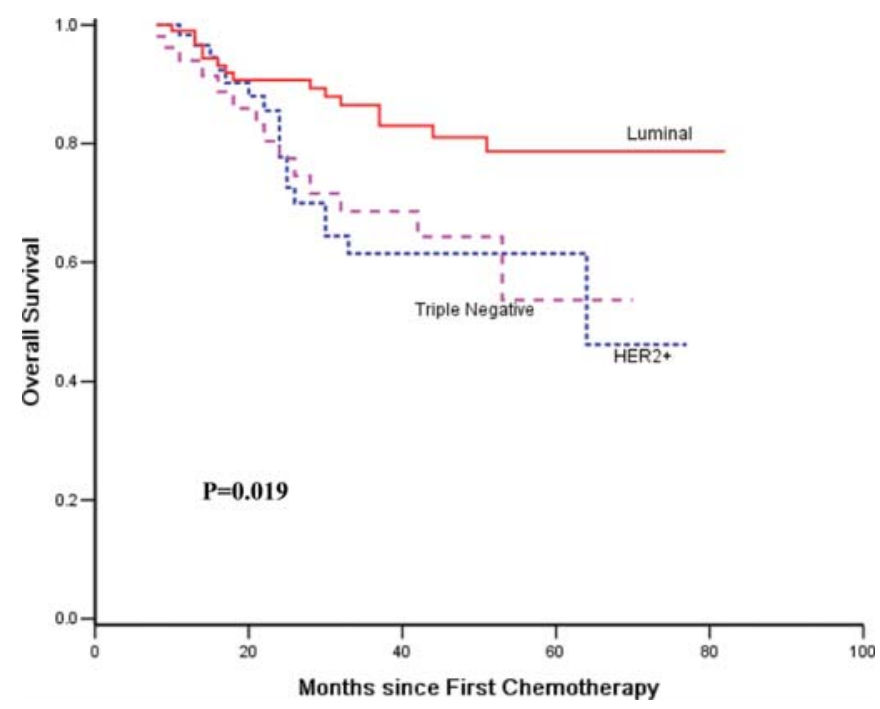

Figure 2. Correlation between breast cancer subtypes and OS in the whole patients.

to predict the OS. Compared with luminal subtype, patients with HER2 positive $(\mathrm{HR}=2.92 ; 95 \% \mathrm{CI}=1.44-5.95 ; \mathrm{P}=0.003)$ or triple negative disease $(\mathrm{HR}=2.90 ; 95 \% \mathrm{CI}=1.37-6.15$; $\mathrm{P}=0.005$ ) had shorter OS. Furthermore, in patients with RD, luminal subtype was also associated with better prognosis, with P-value 0.022 and 0.007 in cases of DFS and OS, respectively (Figs. 5 and 6 ).

\section{Discussion}

Breast cancer is a heterogeneous disease and can be classified with different subtypes using clinical and pathological factors. Microarray results had indentified three major subtypes of breast cancer that had differing prognosis (8). There are several studies using IHC methods to construct this breast cancer subtype and evaluate the relationship between

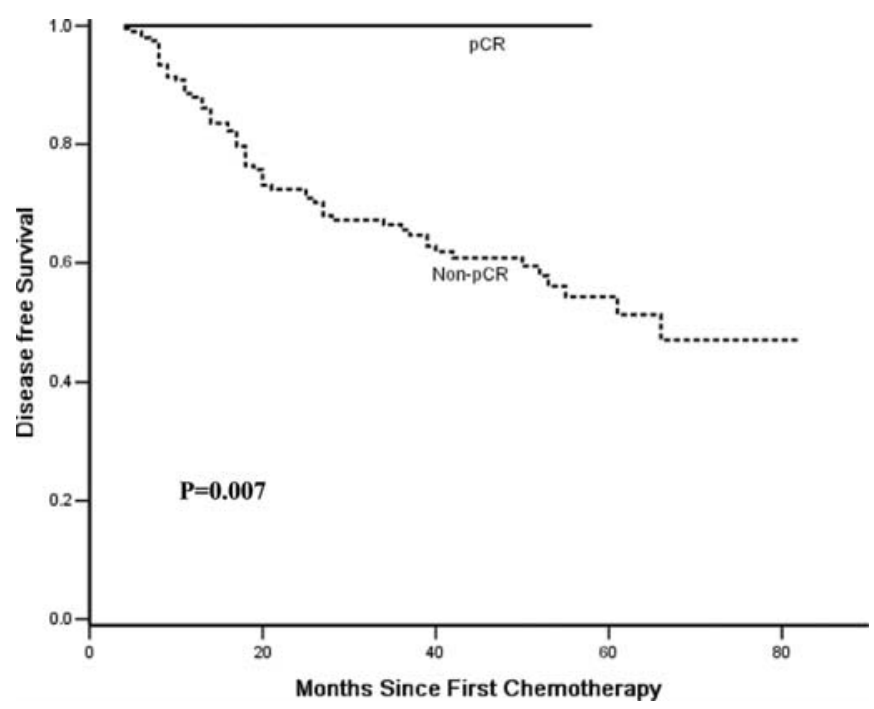

Figure 3. DFS according to pathological response.

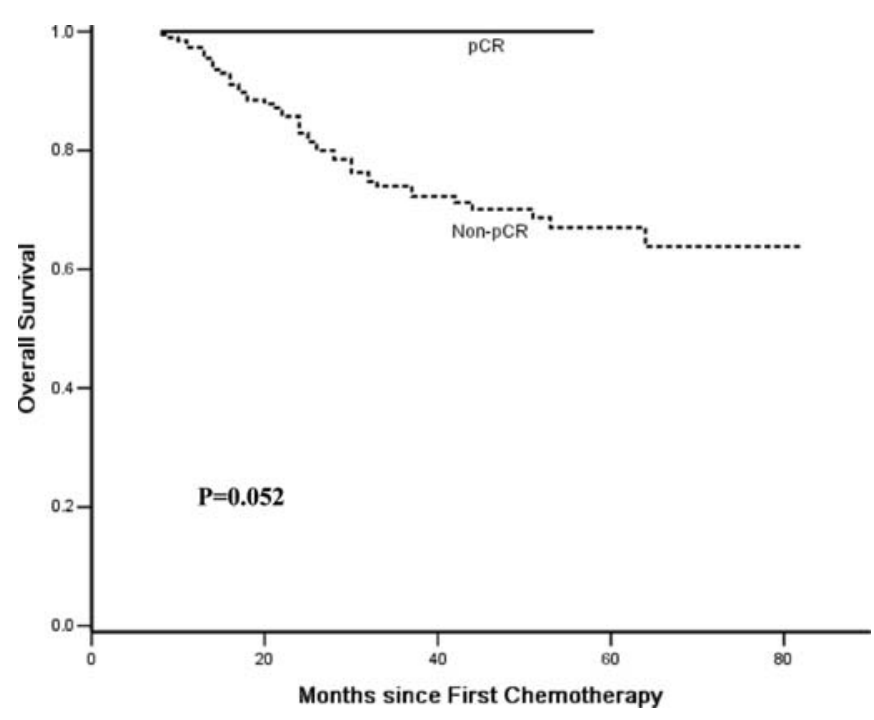

Figure 4. OS according to pathological response.

preoperative response (10-12) and long-term survival $(9,10,13,16,17)$. However, there were relative few studies focused on LABC using this method to predict the response and outcome mainly due to the low incidence in advanced countries (2). Our study aimed to evaluate the predictive and prognostic accuracy of molecular subtype approximately by ER, PR and HER2 in Chinese LABC patients treated with preoperative therapy. In our study, multivariate analysis showed that molecular subtype was an independent factor to predict the pCR rate, compared with luminal breast cancer, patients with triple negative subtype or HER2 positive subtype had higher pCR rate. Moreover, with a mean followup of 32.5 months, patients with triple negative or HER2 positive disease were associated with poor prognosis compared with luminal breast cancer (DFS, $\mathrm{P}=0.072$; OS, $\mathrm{P}=0.019$ ), especially in those patients with $\mathrm{RD}$ (DFS, $\mathrm{P}=0.022$; $\mathrm{OS}, \mathrm{P}=0.007$ ) 


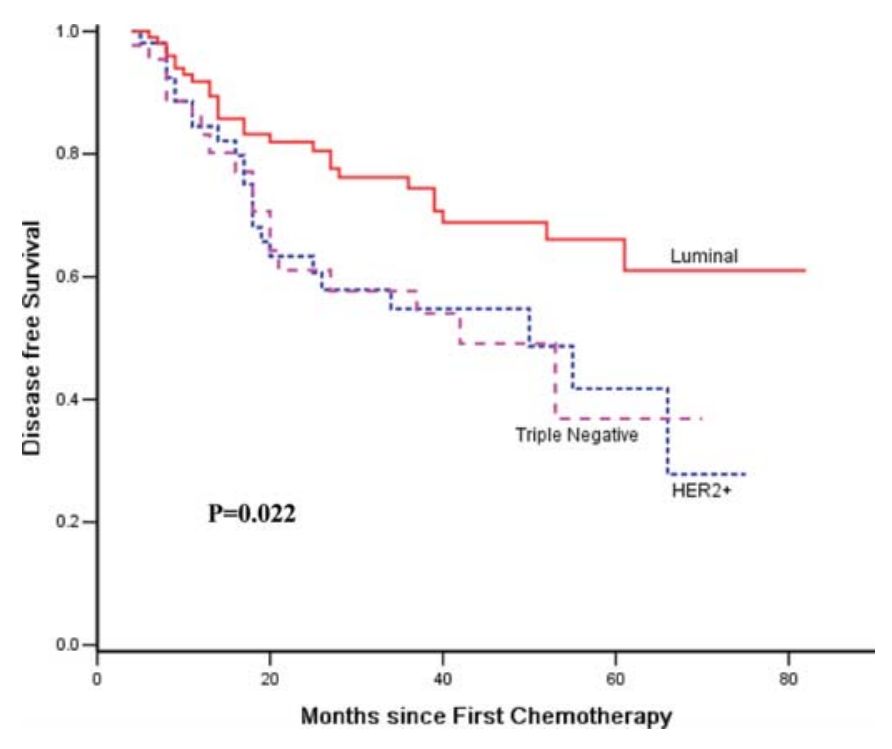

Figure 5. Correlation between breast cancer subtypes and DFS in the non-pCR patients.

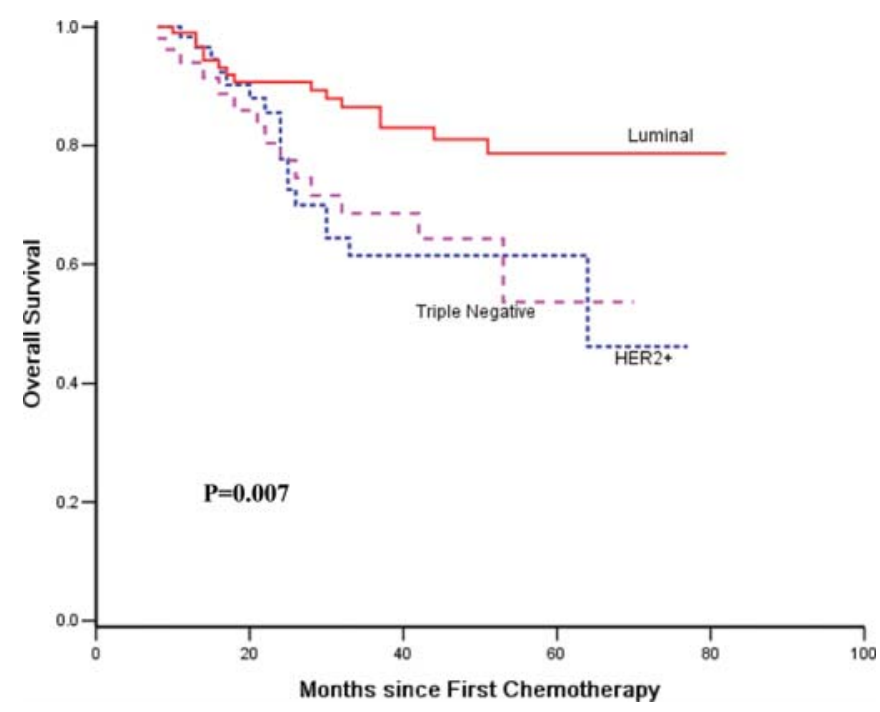

Figure 6. Correlation between breast cancer subtypes and OS in the non-pCR patients.

Approximately $15-25 \%$ of breast cancers exhibited HER2 overexpression (18-20). In our study, 28.9\% Chinese LABC patients were diagnosed with HER2 positive disease which was somewhat higher than these reports, but was similar with a previous report from our center (32.4\% in 1993 patients), however, the incidence of triple negative disease was slightly higher than the previous report (23.6 vs. $18.6 \%)$ which can be explained by the relative advanced stage of disease and the ethnicity of the Chinese Han People (13). In western countries, triple negative breast cancer was associated with relatively large tumors, slightly more nodes involved (21) and high p53 protein expression (22). Bauer et al have also demonstrated that women with triple negative breast cancers were significantly more likely to be under the age of 40 years (16). In our series, the incidence of triple negative disease was also significantly higher in younger patients compared with other subtypes, but there was no difference in clinical tumor stage and regional lymph node involvement among these subtypes, and therefore, it is important to recognize that breast cancer is clinically heterogeneous and should take into account also the race as well as other factors.

Previous reports demonstrated that response to preoperative therapy can predict the subsequent outcome of breast cancer $(4-6,23)$, which makes pCR a valuable intermediate end-point for evaluation efficacy of preoperative therapy regimens. However, the pCR rates of traditional chemotherapy were less than $30 \%$ which indicated that we need further chemosensitive subpopulations or other effective target therapies to improve the response. Rouzier et al demonstrated that using gene expression profiling, patients with basal-like and HER2 positive diseases were associated with the highest rate of pCR, 45 and $45 \%$, respectively, whereas the luminal tumors had a pCR rate of only $6 \%$ (10). In addition, using IHC profiles (ER, PR and HER2) to subtype patients with breast cancer it was found that triple negative and HER2 positive subtypes were more sensitive to anthracycline-based neoadjuvant chemotherapy than luminal diseases (11). Recently, in large series of patients treated with preoperative chemotherapy, triple negative breast cancer also had significantly higher pCR rate than non-triple negative disease (12). In our study, we demonstrated that triple negative and HER2 positive LABC had higher pCR rates, 17.0 and $18.5 \%$, respectively, whereas luminal tumors had only $6.5 \%$, which was similar to these early breast cancer series (13). In studies limited to $\mathrm{ER}^{+}$tumors only, the $\mathrm{pCR}$ rates to combination anthracycline and taxane preoperative chemotherapy were between 6 and 12\%, which may be explained by the high proportion of low recurrence score population in luminal subtype (24). Patients with triple negative or HER2 positive disease had high pCR rates, potential reason was that these two subtypes were characterized by the high expression of the proliferation cluster of genes (8), which is mirrored by other more conventional indexes of proliferation as well.

In large series of early breast cancer not treated with preoperative therapy, HER2 positive had the worst outcome with 11th year recurrence-free survival $72.89 \%$ compared with 75.8 and $78.4 \%$ for triple negative and luminal disease (13). Dent et al showed an increased likelihood of distant recurrence and death within 5 years of diagnosis in triple negative disease of 1601 women with breast cancer (21). In another preoperative therapy study, Carey et al evaluated pCR rates to preoperative chemotherapy in molecular subtypes of breast cancer and found a high pCR rate in the triple negative group which paradoxically had significantly decreased distant DFS and OS compared with the luminal subtype (11). In our series of LABC patients, patients with triple negative and HER2 positive disease both had worse prognosis compared with luminal subtype, especially in patients with RD after preoperative disease, with 5 year estimated DFS 44.2, 45.1 and $67.4 \%$ in the whole population, respectively. Potential reasons may be the advanced stage of disease, relatively small proportions of chemosensitive tumors in triple negative or HER2 positive subtypes, lacking adjuvant 
endocrine therapy in triple negative disease, and excluding HER2 positive patients treated with trastuzumab which has been demonstrated to significantly improve the outcome of HER2 positive breast cancer (25-27). In addition, triple negative or HER2 positive disease remaining RD after preoperative disease, further effective target therapy and other new drugs should be incorporated into treatment to reduce the recurrence rate. However, among those with pCR response, the patients had excellent outcome and all of them remained disease-free in this relative short follow-up period. Given the lower pCR and better outcome in luminal breast cancer, it is possible that pCR is a less useful intermediate end-point for outcome among luminal tumors compared with the other two subtypes.

Our study has some potential limitations due to its retrospective nature. Most of patient received three to four cycles of preoperative chemotherapy and majority received additional adjuvant chemotherapy which may affect the relationship between pathological response and long-term outcome. Besides, we excluded all HER2 positive patients treated with trastuzumab, which was accepted as the standard treatment for HER 2 positive disease, and certainly decreased the survival in this set of population. Finally, HER 2 with $2^{+}$IHC results were classified as HER2- negative disease without FISH confirmation may cause the decreasing size of HER2 positive subtype.

In conclusion, molecular subtype approximated by ER, PR and HER2 can predict the pathological response and prognosis of Chinese LABC patients treated with preoperative therapy. Compared with luminal subtype, patients with HER2 positive or triple negative disease were associated with higher $\mathrm{pCR}$ rates, in addition, those patients who achieved a pCR after preoperative therapy had an excellent outcome. However, patients with HER2 positive or triple negative disease had significantly worse outcome and were associated with increased death and recurrence rates, especially in those with RD after preoperative therapy, which illustrates it is necessary to develop novel target drugs and combinations to improve the outcome for these two subtypes of patients with RD after current preoperative chemotherapies.

\section{Acknowledgements}

The authors thank the patients and family members for their willingness to cooperate with our study. This research was supported in part by the grants from Leading Academic Discipline Project of Shanghai Municipal Education Commission, Project No. J50208.

\section{References}

1. Kaufmann M, Hortobagyi GN, Goldhirsch A, Scholl S, Makris A, Valagussa P, Blohmer JU, Eiermann W, Jackesz R, Jonat W, Lebeau A, Loibl S, Miller W, Seeber S, Semiglazov V, Smith R, Souchon R, Stearns V, Untch M and von Minckwitz G: Recommendations from an international expert panel on the use of neoadjuvant (primary) systemic treatment of operable breast cancer: an update. J Clin Oncol 24: 1940-1949, 2006.

2. Chia S, Swain SM, Byrd DR and Mankoff DA: Locally advanced and inflammatory breast cancer. J Clin Oncol 26: 786-790, 2008 .
3. Kaufmann M, von Minckwitz G, Bear HD, Buzdar A, McGale P, Bonnefoi H, Colleoni M, Denkert C, Eiermann W, Jackesz R, Makris A, Miller W, Pierga JY, Semiglazov V, Schneeweiss A, Souchon R, Stearns V, Untch M and Loibl S: Recommendations from an international expert panel on the use of neoadjuvant (primary) systemic treatment of operable breast cancer: new perspectives 2006. Ann Oncol 18: 1927-1934, 2007.

4. Wolmark N, Wang J, Mamounas E, Bryant J and Fisher B: Preoperative chemotherapy in patients with operable breast cancer: nine-year results from National Surgical Adjuvant Breast and Bowel Project B-18. J Natl Cancer Inst Monogr 30: 96-102, 2001.

5. Bear HD, Anderson S, Brown A, Smith R, Mamounas EP, Fisher B, Margolese R, Theoret H, Soran A, Wickerham DL and Wolmark N; National Surgical Adjuvant Breast and Bowel Project Protocol B-27: The effect on tumor response of adding sequential preoperative docetaxel to preoperative doxorubicin and cyclophosphamide: preliminary results from National Surgical Adjuvant Breast and Bowel Project Protocol B-27. J Clin Oncol 21: 4165-4174, 2003.

6. Rastogi P, Anderson SJ, Bear HD, Geyer CE, Kahlenberg MS, Robidoux A, Margolese RG, Hoehn JL, Vogel VG, Dakhil SR, Tamkus D, King KM, Pajon ER, Wright MJ, Robert J, Paik S, Mamounas EP and Wolmark N: Preoperative chemotherapy: updates of National Surgical Adjuvant Breast and Bowel Project Protocols B-18 and B-27. J Clin Oncol 26: 778-785, 2008.

7. Perou CM, Sørlie T, Eisen MB, van de Rijn M, Jeffrey SS, Rees CA, Pollack JR, Ross DT, Johnsen H, Akslen LA, Fluge O, Pergamenschikov A, Williams C, Zhu SX, Lønning PE, BørresenDale AL, Brown PO and Botstein D: Molecular portraits of human breast tumours. Nature 406: 747-752, 2000.

8. Sørlie T, Perou CM, Tibshirani R, Aas T, Geisler S, Johnsen H, Hastie T, Eisen MB, van de Rijn M, Jeffrey SS, Thorsen T, Quist H, Matese JC, Brown PO, Botstein D, Eystein Lønning P and Børresen-Dale AL: Gene expression patterns of breast carcinomas distinguish tumor subclasses with clinical implications. Proc Natl Acad Sci USA 98: 10869-10874, 2001.

9. Sorlie T, Tibshirani R, Parker J, Hastie T, Marron JS, Nobel A, Deng S, Johnsen H, Pesich R, Geisler S, Demeter J, Perou CM, Lønning PE, Brown PO, Børresen-Dale AL and Botstein D: Repeated observation of breast tumor subtypes in independent gene expression data sets. Proc Natl Acad Sci USA 100: 8418-8423, 2003

10. Rouzier R, Perou CM, Symmans WF, Ibrahim N, Cristofanilli M, Anderson K, Hess KR, Stec J, Ayers M, Wagner P, Morandi P, Fan C, Rabiul I, Ross JS, Hortobagyi GN and Pusztai L: Breast cancer molecular subtypes respond differently to preoperative chemotherapy. Clin Cancer Res 11: 5678-5685, 2005.

11. Carey LA, Dees EC, Sawyer L, Gatti L, Moore DT, Collichio F, Ollila DW, Sartor CI, Graham ML and Perou CM: The triple negative paradox: primary tumor chemosensitivity of breast cancer subtypes. Clin Cancer Res 13: 2329-2334, 2007.

12. Liedtke C, Mazouni C, Hess KR, André F, Tordai A, Mejia JA, Symmans WF, Gonzalez-Angulo AM, Hennessy B, Green M, Cristofanilli M, Hortobagyi GN and Pusztai L: Response to neoadjuvant therapy and long-term survival in patients with triple-negative breast cancer. J Clin Oncol 26: 1275-1281, 2008.

13. Yin WJ, Lu JS, Di GH, Lin YP, Zhou LH, Liu GY, Wu J, Shen KW, Han QX, Shen ZZ and Shao ZM: Clinicopathological features of the triple-negative tumors in Chinese breast cancer patients. Breast Cancer Res Treat 115: 325-333, 2009.

14. Liu ZB, Liu GY, Yang WT, Di GH, Lu JS, Shen KW, Shen ZZ, Shao ZM and Wu J: Triple-negative breast cancer types exhibit a distinct poor clinical characteristic in lymph node-negative Chinese patients. Oncol Rep 20: 987-994, 2008.

15. Hudis CA, Barlow WE, Costantino JP, Gray RJ, Pritchard KI, Chapman JA, Sparano JA, Hunsberger S, Enos RA, Gelber RD and Zujewski JA: Proposal for standardized definitions for efficacy end-points in adjuvant breast cancer trials: the STEEP system. J Clin Oncol 25: 2127-2132, 2007.

16. Bauer KR, Brown M, Cress RD, Parise CA and Caggiano V: Descriptive analysis of estrogen receptor (ER)-negative, progesterone receptor (PR)-negative, and HER2-negative invasive breast cancer, the so-called triple-negative phenotype: a populationbased study from the California Cancer Registry. Cancer 109: 1721-1728, 2007

17. Smid M, Wang Y, Zhang Y, Sieuwerts AM, Yu J, Klijn JG, Foekens JA and Martens JW: Subtypes of breast cancer show preferential site of relapse. Cancer Res 68: 3108-3114, 2008. 
18. Slamon DJ, Clark GM, Wong SG, Levin WJ, Ullrich A and McGuire WL: Human breast cancer: correlation of relapse and survival with amplification of the HER-2/neu oncogene. Science 235: 177-182, 1987.

19. Slamon DJ, Godolphin W, Jones LA, et al: Studies of the HER-2/ neu proto-oncogene in human breast and ovarian cancer. Science 244: 707-712, 1989

20. Pritchard KI, Shepherd LE, O'Malley FP, Andrulis IL, Tu D, Bramwell VH and Levine MN; National Cancer Institute of Canada Clinical Trials Group: HER2 and responsiveness of breast cancer to adjuvant chemotherapy: N Engl J Med 354: 2103-2111, 2006.

21. Dent R, Trudeau M, Pritchard KI, Hanna WM, Kahn HK, Sawka CA, Lickley LA, Rawlinson E, Sun P and Narod SA: Triple-negative breast cancer: clinical features and patterns of recurrence. Clin Cancer Res 13: 4429-4434, 2007.

22. Abd El-Rehim DM, Ball G, Pinder SE, Rakha E, Paish C, Robertson JF, Macmillan D, Blamey RW and Ellis IO: Highthroughput protein expression analysis using tissue microarray technology of a large well-characterised series identifies biologically distinct classes of breast cancer confirming recent cDNA expression analyses. Int J Cancer 116: 340-350, 2005.

23. Carey LA, Metzger R, Dees EC, Collichio F, Sartor CI, Ollila DW, Klauber-DeMore N, Halle J, Sawyer L, Moore DT and Graham ML: American Joint Committee on Cancer tumor-nodemetastasis stage after neoadjuvant chemotherapy and breast cancer outcome. J Natl Cancer Inst 97: 1137-1142, 2005.

24. Gianni L, Zambetti M, Clark K, Baker J, Cronin M, Wu J, Mariani G, Rodriguez J, Carcangiu M, Watson D, Valagussa P, Rouzier R, Symmans WF, Ross JS, Hortobagyi GN, Pusztai L and Shak S: Gene expression profiles in paraffin-embedded core biopsy tissue predict response to chemotherapy in women with locally advanced breast cancer. J Clin Oncol 23: 7265-7277, 2005.
25. Piccart-Gebhart MJ, Procter M, Leyland-Jones B, Goldhirsch A, Untch M, Smith I, Gianni L, Baselga J, Bell R, Jackisch C, Cameron D, Dowsett M, Barrios CH, Steger G, Huang CS, Andersson M, Inbar M, Lichinitser M, Láng I, Nitz U, Iwata H, Thomssen C, Lohrisch C, Suter TM, Rüschoff J, Suto T, Greatorex V, Ward C, Straehle C, McFadden E, Dolci MS and Gelber RD; Herceptin Adjuvant (HERA) Trial Study Team: Trastuzumab after adjuvant chemotherapy in HER2-positive breast cancer. N Engl J Med 353: 1659-1672, 2005.

26. Romond EH, Perez EA, Bryant J, Suman VJ, Geyer CE Jr, Davidson NE, Tan-Chiu E, Martino S, Paik S, Kaufman PA, Swain SM, Pisansky TM, Fehrenbacher L, Kutteh LA, Vogel VG, Visscher DW, Yothers G, Jenkins RB, Brown AM, Dakhil SR, Mamounas EP, Lingle WL, Klein PM, Ingle JN and Wolmark N: Trastuzumab plus adjuvant chemotherapy for operable HER2positive breast cancer. N Engl J Med 353: 1673-1684, 2005.

27. Slamon DJ, Eiermann W and Robert N: Phase III randomized trial comparing doxorubicin and cyclophosphamide followed by docetaxel (ACT) with doxorubicin and cyclophosphamide followed by docetaxel and trastuzumab (ACTH) with docetaxel, carboplatin and trastuzumab (TCH) in HER2-positive early breast cancer patients: BCIRG 006 study. Breast Cancer Res Treat 94: S5, 2005. 